\title{
Gamificação: uma estratégia para auxiliar no dever de casa invertido
}

\section{Eduardo Oliveira do Rosário Júnior}

eduardooliveira260886@gmail.com

Universidade Federal do Pará - UFPA

\author{
Ivanilton Ferreira \\ ferreiranilt@gmail.com \\ Universidade Federal do Pará - UFPA
}

Resumo: O presente estudo vem com o seguinte tema: GAMIFICAÇÃO: Uma Estratégia para Auxiliar no Dever de Casa Invertido. O objetivo principal é contribuir com estratégias didáticas e pedagógicas, usando princípios de jogos para gamificar o dever de casa invertido, como proposta motivadora no intuito de auxiliar no dever de casa. A ideia da gamificação é envolver o aluno nas tarefas, que deveria ser realizada em casa, observando as regras e os objetivos, motivando-os com mecanismos oriundo de jogos, engajando-os e propiciando um ambiente lúdico e envolvente, além de dar feedback, recompensando-os ao final de cada atividade concluída com êxito. O desígnio é despertar a curiosidade, e correlacionando com o objeto de ensino a ser estudado, com isso, desenvolver a criatividade e autonomia dos estudantes. Esta pesquisa parte do princípio que o ensino que inclui elementos de jogos, em geral tende a favorecer o estudante, e para que este possa executar as tarefas sem que erros e fracassos tenham relutâncias. Incluir elementos de jogos para fins didáticos visando promover uma reflexão no tange o processo de ensino aprendizagem, tendo em vista que, algumas atividades para casa são questionadas, por pais e pelos próprios alunos sobre sua eficácia. A metodologia aplicada constituiu-se em uma pesquisa bibliográfica, observando as propostas sugerida por (BERGMANN; SAMS, 2016). E por fim, propomos uma atividade onde o professor possa implementar, sempre que possível, estratégias de jogos para gamificar atividades escolares, com isso deixando as aulas mais dinâmica, e o processo de ensinoaprendizagem ativo.

Palavras-chave: Dever de Casa. Sala de Aula Invertida. Gamaficação.

\section{Introdução}

A sociedade brasileira vem passando por mudanças significativas e desafiadoras. Diante desse cenário de alterações, que ora parte do governo, ora parte da própria sociedade, e a educação não está às margens dessas mudanças.

\section{2) VIA SEGC}


O Censo Escolar de 2017, mostrou índices elevados de evasão escolar, só no Estado do

Pará entre os anos de 2014 e 2015, o índice foi de 16,3\%, no ensino médio. Sabemos que existem vários fatores que influenciam nesses resultados, falta de investimento na educação, professores desmotivados, alunos que questionam algumas práticas e metodologias de ensino que ainda são trabalhadas em sala de aula.

Por isso algumas práticas pedagógicas, que ainda estão presentes em sala de aula são questionadas, sabemos que algumas dessas práxis são controversas e ultrapassadas, onde se baseiam em teorias que não tem sentido para o aluno, e o reflexo disso é o alto índice de evasão escolar. Todavia, nas últimas décadas outras práticas e metodologias vêm conquistando admiradores, que pensam em um processo de ensino que seja significativo para os alunos, como é o caso por exemplo das metodologias ativas, com propostas de ensino centrada no aluno. Embora o termo ganhou destaque principalmente nos últimos anos, "apesar das metodologias ativas não ser novidade, mas a expressão está na moda" (MATTAR, 2017, p. 19-20).

As metodologias ativas têm como princípio a aprendizagem centrada principalmente no aluno, mas, para que essas mudanças cheguem até a sala de aula, ou melhor até o aluno, é necessário que educadores esteja disponível para o novo, Miranda (2016), comenta acerca do assunto com a seguinte reflexão:

sabemos da oposição de muitos colegas educadores à criatividade e à inovação, da resistência à abdicação da sua zona de conforto, representada por rotinas metodologias que cumpre mecanicamente, de olhos fechados, há tempos, e que, na sua visão, sempre deram certo". (MIRANDA, 2016, p. 25)

Portanto, é necessário romper com práticas que não contribui para uma aprendizagem significativa para essa nova geração de alunos. Geração essa tem a disposição várias tecnologias e ferramentas, como smartphones e tablets, que às vezes é visto pelo professor como algo que atrapalha as aulas, mas por que não usar essas ferramentas para como aliado, e assim deixando as aulas mais dinâmica? Para isso, é importante que o professor esteja atento a essas mudanças e transformar, o que na visão de muitos é um problema, em ferramenta que favoreça o processo de ensino e aprendizagem, para (BACICH; MORAN, 2018):

o ensino regular é um espaço importante, pelo peso institucional, anos de certificação e investimentos envolvidos, mas convive com inúmeros outros espaços e formas de aprender mais abertos, sedutores e adaptados às necessidades de cada um. (BACICH, MORAN, 2018, p. 3) 
Quando se fala em novas metodologias e adaptações para o ensino, o educador precisa romper com algumas práticas tradicionais, que às vezes se torna enfadonho para os alunos, ou seja, deve-se pensar em aulas motivadoras e criativas, despertando assim, o desejo no aluno em aprender, usando estratégias didática para suscitar a criatividade, permitindo assim, experiências de aprendizagem que fato seja significativa, nesse sentido, (MIRANDA, 2016), diz que:

as aprendizagens criativas também se originam nas aprendizagens compreensivas e significativas e se referem àquelas em que o aprendente, como sujeito ativo, crítico e reflexivo, produz, na sua singularidade, algo novo com base na informação dada. A aprendizagem criativa transcende ao que lhe apresentado, ganhando sentidos e significados singulares e, por isso, ela também é significativa. (MIRANDA,2016, p. 20).

É importante, porém, (re) pensar em metodologias e técnicas com o intuito de envolver e engajar os alunos e encontrar soluções para as atividades que possam ser resolvidas dentro e fora da sala de aula. Partimos do princípio que a gamificação é uma estratégia bem propícia para auxiliar nesse processo. E, no caso desta pesquisa, a contribuição é no sentido de incluir nas atividades do dever de casa, elementos de jogos para fins didáticos, tendo em vista que a maioria dos alunos possui dispositivos móveis, e tem afinidade com jogos, principalmente os eletrônicos.

Usar estratégias da sala de aula invertida incluindo elementos de jogos para que os alunos possam resolver o dever de casa, usando como estratégia a sala de aula invertida, essa pode ser tática que pode favorecer o aprendizado.

A sala de aula invertida é basicamente a inversão do modelo tradicional, no qual o professor disponibiliza o conteúdo, em casa, o aluno deve resolver as atividades, e em sala o aluno esclarece possíveis dúvidas sobre o conteúdo, com o professor e até mesmo com os colegas. A ideia é que os estudantes tenham contato com o conteúdo, e ao chegarem em sala, para serem então auxiliados pelo professor, e suas dúvidas serem esclarecidas, ajudando na resolução de questões que ficaram pendentes. Com isso tira o professor como detentor do conhecimento.

A posição central do professor no processo de ensino (sábio no palco) começou a ser questionada de maneira mais intensa a partir do momento em que a internet passou a disponibilizar informações e conteúdos gratuitos de qualidade, e em abundância, para qualquer pessoa interessada, criando, assim, espaço para o desenvolvimento de metodologias mais ativas, nas quais o aluno se torna protagonista e assume mais responsabilidade sobre seu

\section{-}


processo de aprendizagem (e o professor se torna um guia ao lado.(MATTAR, 2017, p. 21).

Incluir elementos de jogos para gamificar tarefas do dia a dia da sala de aula, consiste em trazer experiências de jogos para o ensino. A ideia central nessa estratégia, é fazer com que os alunos possam entrar em uma competição saudável, estimulando a interação por meio da ludicidade e estimulando o pensamento criativo, oferecendo possibilidades contextualizadas sobre situações do seu cotidiano. "A gamificação surge como uma possibilidade de conectar a escola ao universo dos jovens com o foco na aprendizagem" (ULBRICHT; BASTISTA; VANZIN, 2014, p. 83).

A prática pedagógica gamificada deve ser desenvolvida usando elementos de jogos, e devem ser pensadas e estruturadas com o propósito de envolver o estudante. Partindo dessa perspectiva, onde o aluno é parte do processo de ensino, a aprendizagem se torna significativa.

Prover o envolvimento dos estudantes para os diferentes ritmos de aprender apoiam uma prática ativa, e podem ser desenvolvidos por meio de atividades gamificadas

\section{Problema da Pesquisa}

A sociedade brasileira vem passando por constantes mudanças, diante dessas mudanças a sala de aula é um espaço que tem a prerrogativa de suscitar nos alunos a criatividade, independência e autonomia para o convívio, tanto no ambiente escolar quanto em sociedade. Este estudo partiu da premissa que a educação transforma a vida das pessoas, e com o intuito de fomentar a inserção de novas metodologias como estratégia para auxiliar no dever de casa. A gamificação surge como possibilidade, colaborando, desse modo, na proposição de estratégias para o enfrentamento das dificuldades encontrado pelo professor.

\section{Objetivo Geral:}

- Contribuir com estratégias didáticas, usando princípios de jogos para auxiliar no dever de casa invertido.

\section{Objetivos Específicos:}

- Fomentar o uso de elementos de games, como estratégia didática.

- Analisar as estratégias usada por educadores, para incentivar os alunos a resolver o dever de casa;

\section{2) VIA SEGC}


- Relacionar as dificuldades encontrada pelos alunos, na execução de atividades proposta pelos professores.

\section{Fundamentação teórica}

$\mathrm{Na}$ aprendizagem baseada em gamificação, o jogador/aprendiz pode escolher como aprender. De acordo com Mattar (2017, p. 79), "traçando um paralelo com a educação, o desafio seria que os alunos atingissem o mesmo nível de maturidade e preparação no controle de seu processo de aprendizagem". Para (NOGUEIRA apud FILATRO; CAVALCANTI, 2018)

construir conhecimento de forma colaborativa é uma tarefa complexa, que requer alto nível de compromisso e gerenciamento de tempo, além da capacidade de levar em consideração outros pontos de vista, negociar significados, distribuir papéis e planejar, ceder e tomar decisões compartilhadas". (FILATRO; CAVALCANTI, 2018, p. 74)

Para envolver o aluno nas atividades, seja no dever de casa ou em outra atividade escolar, é necessário motivá-lo, e usar atividades gamificada, mostra-se uma tendência promissora, percebemos que incluir novos mecanismos no fazer pedagógico, contribui de forma significativa com o ensino, haja vista que, uso de tecnologias e jogos faz parte da cotidiano da maioria dos alunos, além da afinidade com os jogos, para Busarello (2016, p. 31) “as pessoas são motivadas a jogar por quatro razões específicas: para obterem o domínio determinado assunto; para aliviarem o stress; como forma de entretenimento; e como meio de socialização".

Portanto, a utilização de atividades gamificadas no dever de casa, pode contribuir para motivar o aluno a imergir nas tarefas e, consequentemente estimular a aprendizagem proporcionando a ele autonomia para a aquisição de novos conhecimentos.

\section{Metodologia}

O estudo foi desenvolvido a partir de pesquisa bibliográfica. Abordagem foi escolhida tendo em vista os objetivos da pesquisa, principalmente como estratégia didática na compreensão e solução para uma aprendizagem significativa, além de estimular as relações pessoais e a troca de conhecimentos. De acordo com Gil (2002, p. 44) "a pesquisa bibliográfica foi desenvolvida com base em material já elaborado, constituído principalmente de livros e artigos científicos". Foram pesquisados materiais sobre gamificação, sala de aula invertida e metodologias ativas. 
A pesquisa Bibliográfica tem um importante papel no trabalho, pois resgata uma gama de referências que enriquecem o trabalho, vale ressalta que a "[...] a pesquisa bibliográfica, consiste em extrair informações de documentos impressos ou eletrônicos e trabalhá-las, com o objetivo de enriquecer a argumentação no trabalho", (VIEIRA, 2010, p. 95). Com o objetivo de fomentar o uso de gamificação, como estratégias de ensino.

\section{Proposta da atividade:}

A proposta para o dever de casa invertido, surgiu a partir de uma atividade realizada na Disciplina Métodos e Técnicas do PPGCIMES-UFPA, 2019, no qual deveria ser utilizando a Gamificação para resolver o problema do dever de casa, com fundamentação em (FILATRO; CAVALCANTI, 2018).

A ideia desta atividade consiste em um jogo de investigação, no qual os alunos deveriam desvendar enigmas sobre um tema proposto, e que foi disponibilizado em espaços diversos. A primeira pista relacionada ao tema foi enviada aos grupos, assim como o local que cada grupo vai encontrar a questão para desvendar o enigma da atividade do dever de casa invertido.

Esta proposta de atividade foi pensada para o ensino superior, onde foram distribuídas pistas as quais ajudaram aos alunos a desvendarem os valores do Manifesto Ágil para o ensino e Aprendizagem, que de acordo com (FILATRO; CAVALCANTI, 2018, p. 72-73) foi declarado por Krehbiel (2017), que propôs em seu próprio Manifesto Ágil para o Ensino e a Aprendizagem “(Adaptabilidade, Colaboração, Alcance dos resultados de aprendizagem, Investigação dirigida por estudantes, Demonstração e Aplicação e Melhoria Contínua.)". Porém, esta atividade pode ser adaptada para outras etapas do ensino, e pode ser usada em qualquer conteúdo das diversas disciplinas do currículo escolar.

Essa atividade pode ser aplicada da seguinte maneira. Os alunos devem ser divididos em grupos e direcionados para determinados lugares (de preferência dentro da instituição de ensino) que poderá ser uma sala de aula, biblioteca, secretaria, unidade administrativa, etc. onde estará disponível dicas, que pode ser em texto ou áudio.

A aplicação desta atividade foi contendo um conceito que ajudará o aluno a desvendar a qual valor essa dica se refere. Se o aluno acertar o valor correspondente ele receberá a informação para a próximo etapa, onde também deverá encontrar a dica para o próximo enigma, e assim por diante, até que atividade seja concluída. Caso a resposta esteja errada, o grupo não receberá a informação para etapa seguinte, e nesse momento o professor pode conversar com os alunos para identificar as dúvidas e dificuldades encontradas, nesse sentido Bergmann e Sams (2014), corrobora com a seguinte reflexão:

\section{-2: VIA SEGC}


Nós, professores estamos na escola não só para ensinar o currículo, mas também para inspirar, encorajar, ouvir e transmitir uma visão a nossos alunos. E isso acontece em contexto de nossas interações. Sempre acreditamos que o bom professor constrói relacionamentos com os alunos. (BERGMANN e SAMS, 2014, p. 23).

Regras: Os alunos receberão a informação do primeiro local, via aplicativo de mensagem instantânea, que pode ser, por exemplo, o WhatsApp, ou outro meio de comunicação síncrona, após isso, as próximas informações dos locais só serão disponibilizadas aos alunos após eles desvendarem o primeiro enigma, a resposta também deve dar-se-á via aplicativo de mensagem instantânea. Cada resposta correta corresponde a dez (10) pontos, e para as respostas errada, corresponde a menos cinco (-5) pontos para a equipe, e a equipe só receberá a próxima pista quando de fato desvendar o enigma.

A ideia central nessa atividade, é estimular o aluno a conhecer o material disponibilizado para as atividades, além de incentivá-lo para uma atividade colaborativa, com isso romper com o paradigma que o dever de casa é um problema. "São muitas vezes atribuídas sem contexto, são demasiado fáceis ou demasiado difíceis ou são irrelevantes" (BERGMANN; SAMS, 2014, p. 3). Todavia, a gamificação aplicada ao processo de ensino aprendizagem, salienta-se que tais elementos podem ser utilizados na aprendizagem, como motivador aos estudantes.

\section{Análise e discussões}

$\mathrm{Na}$ era das tecnologias digitais, o professor deve estar atento a esses avanços, essa nova era exige dele a compreensão desses avanços. A prática do ensino colaborativo e uma aprendizagem significativa, acontece no coletivo com reflexos para o individual, nessa troca e compartilhamento de aprendizagem, os elementos de jogos pode ser um aliado no processo de geração de conhecimento, além de ser motivador, já que a atividade se torna divertida, nesse sentido, cabe ressaltar o seguinte, "acreditamos que a inversão cria condições para que os professores explorem a tecnologia e melhorem a interação com os alunos" (BERGMANN; SAMS, 2014, p. 22), o professor, portanto, deve ser um entusiasta das novas tecnologias, estimulando um aprendizado ativo e inovador.

Os objetivos e as metas que se deseja alcançar ao gamificar uma atividade escolar, devese está bem clara, assim com as regras para cada etapa de cada atividade/competição, com as etapas definidas e os objetivos explícito que há início meio e fim, e cada participante deve ter

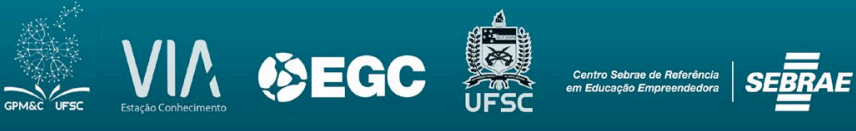


conhecimento. Diante disso, os participantes podem definir suas ações e estratégias com referência no objetivo final do jogo. Por um lado, em situações fora do jogo os mesmos elementos são mais difíceis de serem identificados e alcançados, apesar de poderem existir. Nesse caso cabe ao professor orientar os alunos a sucesso em cada atividade, com isso a relação entre professor aluno pode ficar mais próxima, Bergmann e Sams (2014) falam que: "os professores desempenham papel fundamental na vida dos alunos" (BERGMANN; SAMS, 2014, p. 23). São mentores, amigos, vizinhos e especialistas. Manter interação face a face com os professores é experiência inestimável para o aluno.

Com isso, o espaço escolar se torna um lugar de aprendizagem efetiva, ou seja, onde há compartilhamento de experiências e saberes. Acreditamos também que nesse contexto, a gamificação pode estimular à uma proposta multidisciplinar, interdisciplinar e transdisciplinar, fugindo da ideia de que a busca pelo conhecimento foi fragmentada, rompe ainda com questionamentos de que, para que isso vai me servir, ou, nunca vou aplicar isso que estou aprendendo.

A gamificação é conceito que já vem sendo utilizando, existem alguns aplicativos educacionais, que usam esses elementos em suas plataformas. Como é sabido, os aspectos dos jogos podem contribuir e criar uma relação de proximidade entre os participantes, mas para que os jogadores de fatos se engajam nas atividades, algumas características precisam estar bem claras, como os objetivos.

O objetivo pode variar de acordo com os resultados que se deseja alcançar, e em relação a este trabalho é usar a gamificação no dever de casa invertido.

Outro elemento importante é a regra, de acordo com Ulbricht; Batista; Vanzin (2014, p. 24) “As regras favorecem a liberação da criatividade e do pensamento estratégico, uma vez que buscam ajustar o nível de complexidade do sujeito às atividades a serem realizadas". Destacamos também, outra característica na gamificação que é o Feedback. É importante que o aluno receba as informações sobre sua participação. No jogo por exemplo o participante constantemente está recebendo feedback relacionado ao desempenho, por isso o professor precisa informar ao aluno sobre sua participação e seu desempenho frente a atividade proposta, com isso sentir-se motivado

Pode estar motivado por exemplo de forma intrínseca, ou seja, onde o envolvimento acontece pelo simples prazer na realização da atividade, é autônomo e, a gratificação e satisfação em realizá-la. Ou motivado extrinsecamente, que se refere à realização de uma dada atividade com o objetivo de obter resultados externo, que pode ser material ou social.

\section{-2: VIA SEGC}


As recompensas são fundamentais. Ter o direito a recompensas é a chave para que os jogadores sintam qual o seu valor para suas ações, e que tenha em mente que as recompensas não são necessariamente físicas. Atribuição de pontos por exemplo, é uma forma de recompensar o jogador/estudante.

\section{Considerações Finais}

O objetivo deste trabalho foi desenvolver uma pesquisa bibliográfica, acerca da gamificação, com o intuito de contribuir com estratégias didáticas, usando princípios de jogos para auxiliar no dever de casa invertido, visando as possibilidades que elementos de jogos possa contribuir na motivação dos alunos, em relação ao dever de casa, e com a estratégias da sala de aula invertida, oferecendo assim práticas pedagógicas dinâmicas, com foco na educação, suscitando assim para uma aprendizagem significativa tornando-se um excelente aliado no processo de ensino aprendizagem, principalmente como práticas que visam estimular o educando a empenhar-se nas atividades escolares. Mas para que ocorra essa inversão, o que deveria ser realizado em sala de aula, partindo da perspectiva da sala de aula invertida, poderá ser realizado em casa, nesse sentido, Bergmann e Sams (2014, p. 14), dizem: “como também se oferece um guia de soluções, os alunos são motivados a aprender, em vez de apenas realizar os trabalhos pela memória".

Ao longo das leituras para construção deste trabalho, foi possível identificar várias possibilidades e alternativas que a gamificação proporciona ao ambiente educacional. Entendemos que o ensino e a aprendizagem possuem múltiplas facetas e com muitas distinções, e seu desenvolvendo através de jogos possibilita uma aprendizagem significativa, sem o peso e rigidez de conteúdos que às vezes são sem sentido para o aluno, (CAMARGO; DAROS, 2018):

os modos de ensinar e aprender, o ensino essencialmente transmissivo, centrado unicamente no conhecimento do professor, é motivo para muitas insatisfações. Os alunos reclamam não só do fato de terem que ficar horas ouvindo o professor, mas também da rigidez dos horários, do distanciamento do conteúdo proposto com a vida pessoal e profissional e dos recursos pedagógicos pouco atraente. (CAMARGO; DAROS, 2018, p. 3).

Partindo desse pressuposto, percebe-se que incluir tais elementos para fins pedagógicos, contribui para a dinamização de uma educação mais atraente e significativa. Nessa experiência percebemos o quanto é essencial e necessário o comprometimento com o ensino por meios de

\section{- VIS VIA SEGC}


recursos que os alunos tenham afinidades, com resultados significativos na vida acadêmica dos envolvidos, e com impactos relevantes para a educação.

Com isso, este estudo abordou a inclusão da gamificação, como uma perspectiva motivacional. Entende-se que gamificação parte do princípio de estímulo ao pensar sistematicamente como em jogo, objetivando resolver problemas como o dever de casa. O jogo explora experiências já adquiridas pelos indivíduos, estas são fundamental para a construção do conhecimento do sujeito.

\section{Referências}

BACICH, L.; MORAN, J. (Orgs.). Metodologias ativas para uma educação inovadora: uma abordagem teórico-prática. Porto Alegre: Penso, 2018.

BERGMANN, J.; SAMS, A. Sala de aula invertida: uma metodologia ativa de aprendizagem. Rio de Janeiro: LTC, 2016.

BUSARELLO, R. I. Gamification: princípios e estratégias. São Paulo: Pimenta Cultural, 2016.

CAMARGO, C.; DAROS, T. A sala de aula inovadora: Estratégias Pedagógicas para Fomentar o Aprendizado Ativo. Porto Alegre: Penso, 2018.

FILATRO, A.; CAVALCANTI, C. C. Metodologias Inov-ativas na educação presencial, a distância e corporativa. São Paulo: Saraiva, 2018.

GIL, A. C. Métodos e Técnicas de Pesquisa Social. $6^{\circ}$ ed. São Paulo: Atlas, 2002.

KREHBIEL, T. C. et al. Agile manifesto for teaching and learning. The Journal of Effective Teaching, v. 17. n. 2, p. 90-111, 2017.

MATTAR, J. Metodologias ativas: para uma educação presencial, blended e a distância. São Paulo: Artesanato Educacional, 2017.

MIRANDA, S. de. Estratégias didáticas para aulas criativas. Campinas, SP: Papirus, 2016.

ULBRICHT, R.; BATISTA, C. R.; VANZIN, T. (orgs.). Gamificação na Educação. São Paulo: Cultural, 2014. Disponível em: https://www.pimentacultural.com/gamificacao-naeducacao. Acesso em: 26 set. 2019.

VIEIRA, J. G. S. Metodologia de Pesquisa Científica na Prática. Curitiba: Fael Editora, 2010. Disponível em:

http://www.aedmoodle.ufpa.br/pluginfile.php/230334/mod_resource/content/1/LIVROMetodologia\%20de\%20Pesquisa\%20Cient\%C3\%ADfica\%20na\%20pr\%C3\%A1tica.pdf. Acesso em: 26 set. 2019 